of light is thrown on it. We always test that for ourselves, and it sometimes helps us in determining by further examination some past forgotten illness. It should help us when we come to determine the correction. It is very seldom that they report on the stippling of the macular region which dates back in a nephritis of pregnancy of years ago. It is seldom that they note the slight traces of an old neuroretinitis. You complain that the optometrist has invaded your field. The competent ones frankly treat the eyes as optical instruments and claim to do nothing more. Many of you, for the average case, do nothing more. Of course you do protect the patient in the case of some eye diseases which the optometrist would not be expected to discover; but that is the very least that you can do.

\section{METHODS OF REFRACTION}

And now please allow me to speak of your methods of refraction. I know that this is not the field of the internist; but it is his patient whom you are examining, and he is intensely interested that you succeed. His difficult cases form so small a percentage of your practice and take so much of your time that you would often prefer not to bother with them. But they are the most of our practice, and we need your help. We ask you, therefore, to consider refraction as the highest expression of your art, not as a necessary evil to be endured or handed over to a junior associate. Give it yout best thought. Please be patient; your responsibility is great. We know often from watching you whether or not you will succeed with our patient, so pardon us if we ask you to consider these suggestions.

To begin with, it is fundamental that you first of all determine accurately the static error and all of it. Don't worry: we shall not ask you to correct all of it; but we do ask that you determine all of it before you plan to correct any of it. To do this requires complete paralysis of the muscles of accommodation. Homatropin may be satisfactory for the patients who come to you directly. I don't know anything about them; but if correction is intended to correct more than blurred vision, please use atropin, if possibie. We think your use of cycloplegics is often a good deal of a farce. We ask you to determine the entire error, no matter how slight it is, no matter whether it disturbs vision or not, no matter whether you think it important or not. Those ophthalmologists who have helped us most always begin with a careful retinoscopic examination in order to get the general lay of the land and to guard against a gross error which the patient has learned to suppress. They insist that the distance from the patient when the retinoscopy is performed should be accurately measured and not estimated each time. Then, as the court of last appeal, they use the subjective tests to confirm this result and add details. Then comes the question of muscle balance, muscle strength, ciliary hypertrophy, etc.

At this point I would urge you not to fatigue the patient too much. In colorimetric work we do not allow the student to use one eye more than fifteen seconds at a time, and require that he determine this period accurately with a watch. While the fatigue during the refraction test may not be as rapid, yet we know that fatigue is important and does explain some poor results. The harder some of our friends try, the worse results they get; for the more pains they take, the more conscientiously they work, the more fatigued the patient's eyes get. The static error accurately determined, the tests repeated and checked up, then the question arises, How shall we meet it? and in answering that please allow us some voice. The formula of the error does not mathematically determine the formula for the glasses. Three men agreeing on the error might differ markedly in the glasses they would prescribe, and their differences would probably depend on their estimation of the patient, and we know our nervous patient much better than can you. In the case of your average patient you may follow certain general rules with average good results. But these cases I am now discussing are not average cases, and we internists who have examined them as individuals, not as seeing mechanisms, know well that you can make or break our chances of helping them. Some of these patients are hyperesthetic, some rather anesthetic; some are hypertonic, some more atonic. I remember one ophthalmologist who watched the patients as they walked to his chair, noted their stride, their posture, their snap; who pinched their arms to determine their muscular tonicity, and who talked to them to form some estimate of their mental tone. Do you? We have struggled with these same persons before we referred them to you. Cannot ophthalmologist and internist talk over the patient and together decide concerning the correction to be prescribed? You will need to teach us a great deal before we can help you much, but we are confident that if you will teach us how we can help them our patients will profit much as a result. Tonsils are no longer a local problem. The specialist in diseases of the throat has learned to discuss them in terms of heart, joints and kidneys. The nose is no longer entirely a local problem, for the rhinologist now consults with internists concerning the patient's asthma and dysmenorrhea. The internists now are struggling to relieve patients with neurasthenic reactions, and we ask you to come over into the field of neurologic ophthalmology and help us.

\section{NECESSARY BUT OFTEN NEGLECTED REFINEMENTS IN EXAMINATION OF OCULAR REFRACTION *}

WALTER L. PYLE, M.D. PHILADELPHIA

The examination and correction of errors of ocular refraction may be called an art. Preparatory scientific study is, of course, necessary; but without the proper mental attitude-an absolute belief in the importance of correcting small refractive errors, the best work is not possible. Long practice, infinite care, and attention to finer details are imperative requisites. It is an established fact that many of the worst sufferers of ametropic eyestrain are the subjects of small optical errors. Astigmatism is the important defect, and on its proper diagnosis and treatment rests most of the ophthalmologist's success.

A slight fault in the correction of refractive errors aggravates rather than relieves the accompanying asthenopic symptoms. By applying sufficient optical aid to allow the ciliary muscle to compensate perfectly for the uncorrected refractive defect, continuous rather than intermittent ametropic eyestrain is established.

* Read before the Section on Ophthalmology at the Seventieth Annual Session of the American Medical Association, Atlantic City, N. J., June, 1919. 
In such cases the sufferers, apparently visually competent and resting assured that their lenses are correct, vainly seek elsewhere for relief from symptoms obviously of asthenopic origin. It is the experience of every careful American medical refractionist employing modern methods and refinements in technic that the exact optical correction, even though the change in lens be small (and by some unfortunately considered negligible), is often followed by brilliant results in apparently hopeless cases. It is common to relieve such persons, after they have exhausted their patience and finances in a weary and hopeless round of medical and surgical specialists, tenotomists, refracting opticians, physical culturists, Christian scientists, osteopaths, and endless other faddists and "pathists."

The observations herewith recorded have been suggested during an extensive ophthalmic practice extending over twenty-five years and devoted chiefly to the correction of ametropia in my private office. Thousands of examinations of refraction in a great variety of patients, of all ages and conditions, have been carefully recorded and preserved. The suggestions are not offered as especially original or unique, but they are all of striking value in routine office practice.

THE EXAMINATION ROOM

I have always worked in a room facing the north, allowing uniform light, without the periodic interruptions of direct sunlight. The patient is placed in the refracting chair with his back to a rear window, a n d 10 oks toward the darkest corner of the room. There are no side windows to dazzle or disturb. All lighting is from behind or overhead. The examiner sits on a stocl facing the window, and in front of his table of test lenses. The patient is placed on a revolving seat in a chair with short arms. It is desirable to have the eyes of the examiner and those of the patient on about the same level. With children and small adults there is used an adjustable foot rest attached to the chair. This may be elevated or lowered, to allow such patients to rest their feet comfortably.

A rigid position of the head is insisted on, and with chronic head tilters, the head is fixed mechanically as in the old-fashioned photograph galleries. The patient is also urged to maintain the upright position, and not slouch down in the chair or cross the legs. Attached to the back of the patient's chair is a large, movable, black, metallic screen to surround the back of the head and to prevent reflections from the surfaces of the lenses applied. In some instances, draping a handkerchief over the head of the patient will be found most satisfactory. When so shielded from the rear glares, it is surprising how quickly the patient notices the relief from the lens-surface reflections.

TEST LENSES AND LENS TESTING DEVICES

It is rare to find a perfect set of test lenses, even in private offices. In hospitals and clinics, the test lenses are especially faulty, and generally dirty or permanently soiled. The stock test lenses are made to be sold at a moderate price, and it is commercially impossible for the optical manufacturers to guarantee perfection. In examining the cylinders, there will usually be found from 10 to 50 per cent. of errors as to exact centering and marking of the axes. Even with the help of reliable private prescription opticians, it took months before I could be satisfied that I possessed an absolutely perfect set of test lenses.

Every oculist should possess or have access to a mechanical lens measure, axis finder and centering machine. The oculist should also insist that the opticians who receive his prescriptions use such apparatus. Especially praiseworthy are the Geneva and Standard instruments and the Lloyd axometer. I use for centering and axis finding the instrument called by the trade name of "the Revelation," which is compact and cheap, and has proved very satisfactory for office work.

Of course, it is not reasonable to demand that the oculist so completely test all the lenses submitted to him for approval; but he should, first, thoroughly examine and verify his own test lenses, and then test a sufficient number of opticians' lenses to satisfy himself that they are careful, and also to impress on them that their work will be checked closely. If the oculist practices sufficient $\mathrm{c}$ a $\mathrm{r}$ e and accuracy in his examinations to prescribe the proper lenses, there is no excuse for the optician, always receiving a reasonable profit for his work, to fail to employ similar care in grinding and fitting the lenses.

I am not prepared to give exact personal statistics as to opticians' errors, but they are unnecessarily numerous and they must be startling in the rural sections where the lenses are ordered by mail from

Hartshorne and W. M. Richards of New York report figures collected from personal examinations that show a high percentage of errors in the work of reputable city.prescription specialists; and they practically challenge much of the lens work of manufacturers. It seems that in the quest for pure food and pure drug laws, some official attention might be directed to the dispensing of correct optical lenses-a semimedical and hygienic function.

The proper grinding and accurate centering of spherical lenses is not difficult, but properly to prepare cylindric lenses is different. The exact axis should be marked by short lines extending from the very periphery of the lens. The test-lens cells should be $11 / 2$ inches in diameter, and both the spheres and cylinders should have handles at least three-fourths inch long, with the quality and strength of their curves plainly stamped in white. The convex lenses are in silverplated cells, and the concave in gold-plated cells.

Spheres and cylinders of $0.25 \mathrm{D}$. curve, mounted in cells with special handles about $2 \frac{1}{2}$ inches long, are much more satisfactory than the regular case lenses in making the front tests. Refraction examinations should be ended by using cross-cylinders of $0.25 \mathrm{D}$. curve, similarly mounted with longer handles. 
Before definitely recording the refraction findings, the exact axis of the astigmatism of each eye should be confirmed by placing a blinder in one side of the trial frame, and observing whether tilting the frame or the head to one side or the other improves the vision. Several such trials should be made, and if the patient is insistent on distinct visual improvement by the tilting of the frame or head, his statement should be confirmed by repeated rotations in the trial frame of the suspected cylinder.

\section{NECESSITY OF RETURN VISITS}

The importance of inspection and examination of opticians' lenses is obvious. I also instruct my patients to return after subsequent repairs if there is even a slight discomfort with the replaced lenses. I always request a return visit from new patients after they have worn their lenses for two or three months, whether or not they have had suspicious symptoms. Occasionally, I find an early reexamination of the refraction advisable. The sudden relaxation of the muscular strain, both intra-ocular and extra-ocular, may be followed by an early change in astigmatism, especially in the axis. In short, to be safe I always question the accuracy of any lenses that do not give reasonably continuous relief after several weeks' trial. In such cases, I explain that the early change of lens has been unavoidable. and imperative; that the human eyeball is a living. organism and hence strbject to constant change, while the correcting lenses are unchangeable in physical qualities.

It is also my custom especially to direct my patients just when to return for routine reexamination. This time is fixed by the age and health of the patient, by the type of optical defect, the case history, and the previous changes noted. Generally speaking, a brief annual test should be made, to be followed by a complete reexamination if deemed necessary.

\section{TEST CHARTS}

I prefer to place my test cards at a distance of 6 meters from my patients' eyes, and on about the same level. For many years, I have employed block letters, showing white on a black background. These cards are not so likely to become soiled, and the letters are read with greater ease than on the white card with black letters.

I use a standard and invariable illumination with two 40 candle power Mazda lights and a parabolic reflector extending over the top of the cards, following the suggestion of Dr. Mortimer Frank of Chicago. However, it is likely that satisfactory illumination may be made from the side.

The test charts should be so placed that from the patient's chair no reflection is seen from the surface of the card. I have never seen a test card without a highly reflecting surface, and I always correct this by proper angling in the relation to the source of light and the position of the patient's head. The glare from the ordinary astigmatic charts especially renders them unsatisfactory, and only occasionally do I use them. In a trained patient, after a preliminary retinoscopy, the trial cylinders, properly employed, are quite sufficient for satisfactory results.

A comprehensive study of astigmatic charts has been made by Dr. Walter B. Lancaster of Boston, and he has constructed an improved chart in which the lines, instead of being printed, have been made with black velvet ribbon (baby ribbon No. 1 or $11 / 2$ in the stores) glued to a very white card of so-called "wedding stock." I have one of these charts in my office, but as I have already said I seldom have use for the astigmatic lines, and I have never found that they expedited my examinations.

\section{OBJECTIVE METHODS}

Objective methods are almost indispensable in cases of illiterate persons and children. They are great time savers in hospital and dispensary clinics, but I find myself relying on them less and less. The so-called optometers I have long since discarded. The ophthalmometer I use only in experimental study of corneal curves, especially after an operation or injury. I have never prescribed cylindric lenses from the ophthalmometric examination alone.

Retinoscopy, or the shadow test, is by far the most convenient and reliable of the objective tests, but it is only suggestive and not accurate. $\mathrm{Al}$ though I employ retinoscopy constantly in my routine office work, in only a few cases is it indispensable; and I never allow it to influence my subjective findings. I have noticed that ophthalmologists who become so proficient in retinoscopy that they have allowed their objective findings to infuence their subjective tests have not been noted for the accuracy of their prescribed lenses. The subjective methods of refraction must be the ultimate guide. In intelligent patients they can be practiced with absolute precision and in a comparatively short time; and it is in patients of education and culture that the ultimate fineness of correction is demanded. Only by subjective examination can the entire visual apparatus-from the end-organ to the visual centers-be tested.

Crude and speedy objective methods are adapted for refraction work only in the illiterate and lower dispensary classes. Illiterates not using their eyes intensely in close work are seldom sensitive to ametropic eyestrain. However, in illiterate seamstresses or similar eye workers, $I$ always use the subjective methods with illiterate test charts, and never rest secure on my retinoscopic findings alone.

As soon as possible in children, and this in America is always at an early age, I attempt a careful subjective examination, and prescribe an accurate correction. In infants, of course, only retinoscopy is available; but I do not feel safe in allowing the retinoscopic correction to be worn more than two or three years without reexamination. 
TIIE TRIAL FRAME

The prime requisites for the trial frame are rigidity, lightness, proper position on the face, and ease of general adjustment and manipulation of the trial lenses. There is also a necessity for individual adjustment of the two sides, to pernit perfect binocular centering. The ideal trial frame would also allow independent bilateral, vertical and anteroposterior adjustments; but this would necessitate too much mechanism, and would be too expensive and too heavy. Such complicated construction is not necessary in ordinary office work.

It is most important that the trial frame shall be firmly and snugly placed on the sides of the nose and adjacent cheeks, in approximately the position in which the prospective spectacles or eye glasses will be worn. In this respect all frames fixed to mechanical instruments, such as optometers, are at fault, are often clumsy, and are signally deficient for accurate testing. The frame should be grooved and slotted to allow rotation of the cylinders at least 180 degrees. The rotation should be effected by light contact with the tip of the first finger. It is impossible to practice noiseless and smooth rotation, when using cells without handles. The placing of the trial lenses in the spring clips is awkward, disconcerting to the patient, and trying to the oculist. Only by the use of a properly grooved and slotted trial frame can the ideal examination of the refraction be made.

The ordinary trial frames seldom conform to the modern standards of skilful medical refractionists. In hospitals and dispensaries they are especially faulty and often ludicrous. For many years I used one of three trial frames made under the direction of Dr. George M. Gould. In 1917, I showed to this section a modification of this trial frame conforming to the modern requirements, but it was lacking in the necessary central universal adjustment. Last year, I exhibited at a meeting of the American Ophthalmological Society an improved trial frame having a universal vertical and horizontal adjustment by rack and pinion, placed in the center of the frame, permitting adaptation for any peculiar facial conformation.

The frame is grooved for two lenses. The front groove, for the cylinders, is slotted to allow rotation of the cells with handles. A third test lens may be placed in front of the frame, resting on three small hooks. The test lenses, carefully centered, should be placed before the eyes, properly inclined, and just clearing the eyelashes. The bridge of the frame should not wound the shin or cause irritation or pain. Rotation of the cylindric lenses must be easy, silent and unnoticeable, to prevent even momentary diversion of the patient's attention.

The bilateral independent adjustment is effected by two double screws, operated on the upper outer sides of the frame. The frame is placed on the face, quickly set by the universal adjustment, and supplemented when necessary by movement of the independent double screw adjustment, until the lenses are properly centered. Broad shell coverings on the inner sides of the two cell holders permit the snug application of the frame to the sides of the nose and cheeks. The nose piece proper is used only to fix and maintain the proper position. The graduated semicircles are enameled in dull black, and marked with distinct white lines and figures, allowing the maximal ease in reading the axes. The whole frame is finished dark and dull to prevent annoying reflections.

\section{CYCLOPLEGICS AND MYDRIATICS}

Unless they are contraindicated by age or disease, I always use a cycloplegic and mydriatic in the examination of refraction. Cycloplegia permits study of the static refraction, and mydriasis facilitates retinoscopy and ophthalmoscopy.

My routine custom is to instil from 1 to 6 drops of a solution containing homatropin hydrobromate, $21 / 2$ grains; cocain hydrochlorate, 11/4 grains; distilled water, 2 drams. I use this cycloplegic personally and exclusively in my private office, and never prescribe it for home use. If more than 1 drop is necessary, I instil the additional drops at intervals of fifteen minutes. I seldom use more than 4 drops. The cycloplegia may be partly corrected by the instillation of 1 drop of a 0.5 per cent. solution of physostigmin salicylate. Beyond a sense of slight twitching, there is no objection to the counteracting drop. In many thousands of cases, I have never seen severe untoward results from inducing cycloplegia according to the foregoing method.

Only occasionally for therapeutic purposes do I ever use a stronger cycloplegic; and then $I$ prefer a 1 per cent. solution of atropin sulphate.

1931 Chestnut Street.

\section{THE PRESENT STATUS OF REFRAC- TION WORK *}

\section{E. J. GARDINER, A.B., M.D. \\ CHICAGO}

Following the track sparsely blazed by Young, Whewell, Ware and Airy, Donders cleared the ground and laid the foundations of modern ophthalmology. The obstructions in his path were many and formidable, but his genius enabled him to surmount them, and his epoch-making book on "Accommodation and Refraction of the Eye" at once raised ophthalmology from a purely empiric practice to a quasiexact science. When one considers that up to his time the true nature of hypermetropia, myopia and astigmatism was unknown, that asthenopia was classed as a disease, and that the instruments at his disposal were few and crude, one marvels at the mind that was able, out of this slough of ignorance, to evolve a science that immediately placed ophthalmology at the forefront of the medical specialties. How accurate and exhaustive were his investigations, and how sound were his conclusions is evidenced by the fact that although, since his day, a complicated superstructure has been raised on the foundation that he laid, not one stone thereof has been removed.

Since the publication of Donders' work until the present time, the ingenuity of ophthalmologists has been hard at work improving old instruments of precision and devising new ones, with the result that today our armamentarium is so extensive that there are few problems pertaining to the detection and measurement of muscle anomalies and errors of refraction for the solution of which there are not one or more excellent devices.

The question is, What are we doing with this rich heritage? Are the scientific principles and practical instructions handed down to us being applied in our

* Read before the Section on Ophthalmology at the Seventieth Annual Session of the American Medical Association, Atlantic City,
N. J., June, 1919. 